\title{
Assessment of Factors Affecting the Establishment of Hospitals in Iran
}

\author{
Mohammadkarim Bahadori ${ }^{1}$, Ehsan Teymourzadeh ${ }^{1}$, Seyed Mojtaba Hosseini ${ }^{2}$, Gholam Hossein Alishiri ${ }^{3}$, Ali Ayoubian ${ }^{2}{ }^{*}$ \\ ${ }^{1}$ Health Management Research Center, Baqiyatallah University of Medical Sciences, Tehran, Iran \\ ${ }^{2}$ Department of Health Services Management, Tehran North Branch, Islamic Azad University, Tehran, Iran \\ ${ }^{3}$ Department of Clinical Research, Baqiyatallah Hospital, Tehran, Iran
}

*Corresponding Author: Ali Ayoubian, Ph.D. Student in Health Services Management, Department of Health Services Management, Tehran North Branch, Islamic Azad University, Tehran, Iran. Tel: +98-21-82483250, Fax: +98-21-8840106

Email: a.ayoubian64@gmail.com

Received: 30 Sep. 2015; Accepted: 2 Nov. 2015; Online Published: 11 Jan. 2016

\begin{abstract}
Background: It is important to set up hospitals, since they play a key role in providing health care services based on the budget allocated to the health sector.

Objective: This study evaluated factors militating against the establishment of hospitals in Iran. It also emphasized the importance of health care services.

Methods: This cross-sectional study was conducted in 2012 using a qualitative approach. The study sample consisted of 22 people, officials, administrators and health experts who were recruited by purposeful selection. In order to collect data, a semi-structured interview was conducted. Data was analyzed using an Atlas-Ti software.

Results: Analysis of the interviews suggest that the issue of providing services in terms of ease of access and equity in the allocation of health services is also the focus of particular attention. The socio-economic status of regions were examined in terms of the need for poverty alleviation, equity in health and well-being of interest to industry participants. The survey interviews revealed that the issue of financing and human resources for provincial hospitals, were the key challenges raised by participants in the study.

Conclusion: According to the findings of this study, feasibility studies and evidence-based management optimal decisions were adopted in order to build and operate hospitals in the provinces.
\end{abstract}

Keywords: Establishment, Hospitals, Iran

\section{Background}

Access to health care is a key issue to organizations providing health care services. Hence, one of the main objectives of policy-makers in the health care sector is to facilitate access to health services, so that every member of the society can suitably benefit. People's access to health care is considered as a fundamental right and social goal, hence all individuals are entitled to receive quality health care [1-3].

Several factors have been identified to have influence on access to health care services. These factors include the 3 categories of structural factors (organizations, health care providers, transportation systems), financial factors (the level of insurance coverage and public and governmental supports), and personal factors (culture, income, and personal education and knowledge), which have a significant impact on people's access to services provided in health centers [4-6].

With recent developments, health services have changed in the form, content, and priorities of human issues in all areas and this change has led to new needs and expectations. Economic, social and cultural conditions, family structures, patterns of diseases, and life qualities have changed, thus leading to reduced mortalities and enhanced life expectancies and subsequently, higher importance of access to health services and their qualities. Service providers play a greater role in developing, maintaining, and improving people's health $[1,2]$. Today, equitable access to health services is considered as a very important issue to administrators and recipients of services so that governments sometimes seek their national and global reputations in facilitating equitable access of their citizens to services [2, 4, 6-8].

Hospitals, on one hand, as centers of health services and on the other hand, as centers possessing a great share of the health system budgets, are very important. Hence, efforts have been made to make this center an option for facilitating equitable access to health services. Thus, the creation of hospitals should be undoubtedly focused on the needs of the society within the framework of scientific integrated studies, based on the recognition of needs and evaluation of equipment and facilities [9].

The results of Amerioon's study [3] suggest that resources are often allocated unevenly in developing countries as a result of lack of background information, skills, and expertise in the field of health planning. In a study by Sharifzadegan [8] entitled "Spatial inequalities in access to health services", it was argued that people who are living in low urban areas due to poor financial abilities are more deprived of access to such services due to growth of spatial and social inequalities.

Asefzadeh [10] stated that in the future, a lot of changes in demographics, arrival of new technologies, rising of costs, increased demands for services, and people's enhanced expectations without hesitation will be experienced. Thus, it is mandatory to determine several issues, such as whether the current hospitals are efficient or if new hospitals should be built.

In another research conducted in Iran by Asefzadeh [11] entitled "Assessment of the need to establish new hospitals", it was noted that many aspects must be inevitably considered for the establishment of new 
hospitals, thus putting them in the form of a research project in order of preference in response to the following questions: What is the priority of providing hospitalization services in the area? Where should the new hospitals be established? What capacities should they have? What special services should be provided? How can the existing hospitals be developed in accordance with the present and future changes? How should healthcare be distributed within the healthcare system? How much investment is needed? How can outputs be optimized? In his study, Khayatan [5], concluded that among the four: personal, geographic, financial, and structural factors affecting access to health care services, the geographical factor, which include cases such as distance from home to the serviceproviding center and the center position, had the highest affective coefficient. Therefore, the establishment of medical centers in a proper location, to which the majority of people of the area can have easy access has been significantly mentioned.

\section{Objective}

One of the main issues which is always raised in Iran, is the establishment of hospitals in provincial centers, a decision that requires careful field studies. In this regard, this research aimed to explain the need to set up hospitals in provinces using precise scientific reviews.

\section{Methods}

This study was based on a descriptive-analytical approach qualitatively conducted in 2012. The samples consisted of 22 healthcare officials, administrators, and experts selected using purposive sampling. The participants included the chairmen of healthcare centers and Health Organizations, Deputy of Health and Medical Education, and the health authorities of Alborz, Ilam, Chahar Mahal and Bakhtiari, Qom, Gilan, Hamedan, South, North, and Central Khorasan, Zanjan, Sistan and Baluchestan, Kohgiluyeh and Boyer Ahmad, Golestan, Lorestan, Mazandaran, and Markazi provinces.

To collect data in this study, some semi-structured interviews were employed, for which the initial scope of the questions was determined after the collected sources and data were reviewed by the research group. The main research questions were designed by conducting a number of in-depth interviews with policy-makers and experts. Consequently, 14 questions were designed within the 3 categories: descriptive, structural, and distinctive questions, among which 5 questions were selected as the main questions.

All the interviews were recorded and later transcribed. The average duration of interviews was 60-80 min. The questions were designed in a way that questioned the views and beliefs of the people interviewed on the study subject. Data validity was confirmed by obtaining the complementary comments of the experts and reviews of the participants' manuscripts. Furthermore, a framework analysis was used to analyze the data.

Framework analysis is a method used for analyzing data in qualitative studies, which was initially developed to analyze the data in social studies. It consists of 5 stages: familiarization, understanding of the conceptual framework, coding, drawing of tables, as well as mapping and interpretation of data. In this study, in the familiarity stage of the framework, a form containing information about individuals and a summary of the content of each interview was compiled. To develop a basic conceptual guideline form, frequent meetings were held between researchers to discuss about the issue. Thereafter, through the frequent reviews of each interview (performed at the familiarization stage), the conceptual framework was examined. Each of the interviews was individually coded and a list of the codes together with their relationships with the conceptual framework was extracted from the interviews. At this stage, each part of the relevant data in the interviews was given a code, which was then assessed and reviewed if necessary by holding several meetings. This process was repeated for each interview several times and then tables were drawn so as to compare the interviewees' views on each of the main issues and specify the relationship between each of the major and minor themes. The interpretation of each component of the conceptual model was done in a process similar to the coding stage and ultimately the conceptual framework formed during the analytical process was revised several times. It should be noted that in all the aforementioned stages, Atlas-Ti software applicable in the data analysis of qualitative studies was utilized.

Permission to record the interviewees' voices was obtained and they were assured of the confidentiality of their personal information. In this study, lack of the participants' commitments to attend the interviews was regarded as ethical consideration.

\section{Results}

Concerning the need to set up hospitals in 17 provinces under study, $100 \%$ of the participants considered it as a priority in providing health services and greatly emphasized on this necessity.

Among the most important reasons justifying the establishment of hospitals, numerous problems such as deprivation, size, and high population under coverage $\left(\mathrm{M}_{1}\right.$, $\mathrm{M}_{4}, \mathrm{M}_{13}$, and $\left.\mathrm{M}_{17}\right)$. Only in one of the interviews, was it mentioned that there is no need to build a new hospital in many provinces at the present time $\left(\mathrm{M}_{5}\right)$.

\subsection{The Major Reasons for Setting up Hospitals in Provinces}

Table 1 shows the extraction of a total of 32 codes in response to the mentioned question. Following reviews by experts, the 32 extracted codes were classified into 7 categories (issues), in which $2,6,6,6,2$, and 2 codes were appropriated in the issues of providing services, nature of security, geographical location, socio-economic status, health status, and population under coverage, respectively.

Table 2 shows that a total of 18 codes were extracted in response to the question of the necessary requirements to set up hospitals in the province.

In a total of 18 extracted codes, 5, 5, 3, 3, and 2 codes were allocated to the issues of physical space and appropriate facilities, human resources, centers of service providers, management, integrity and acceptability of medicare delivery, respectively.

Table 3 shows a total of 16 codes extracted in response to the question of obstacles to set up hospitals in the province. After the surveys were conducted, 17 extracted codes were classified into 4 categories, in which 7, 4, 3, and 2 codes were assigned to the subjects of resources, laws, rules, and regulations, costs and the ineffectiveness of other service providers, and provincial location, respectively.

Table 4 shows that a total of 16 codes were extracted in response to the question of one's expectations of the 
authorities to set up hospitals in the province.

Table 1. The codes and sub-codes extracted from the question "What are the most important reasons to set up hospital in this province in your opinion?"

\begin{tabular}{|c|c|}
\hline Categories & Extracted Codes \\
\hline Health condition & $\begin{array}{l}\text { The need to reduce health problems in the province } \\
\text { Common diseases }\end{array}$ \\
\hline \multirow{6}{*}{$\begin{array}{l}\text { Geographical } \\
\text { location }\end{array}$} & Geographical border of the province \\
\hline & Special regional location \\
\hline & Provincial distance from big cities \\
\hline & Regional and provincial locations \\
\hline & Great distance to the nearest health center \\
\hline & Provincial determination \\
\hline \multirow{2}{*}{$\begin{array}{l}\text { Population } \\
\text { coverage }\end{array}$} & Large number of patients existing in the province \\
\hline & Immigrant receptivity \\
\hline \multirow{6}{*}{$\begin{array}{l}\text { Socio-economic } \\
\text { status }\end{array}$} & High deductibility of healthcare \\
\hline & Supply and demand \\
\hline & Equity in healthcare \\
\hline & $\begin{array}{l}\text { High cost of referring to hospitals in other } \\
\text { provinces }\end{array}$ \\
\hline & $\begin{array}{l}\text { A need for poverty elimination and fair access to } \\
\text { services }\end{array}$ \\
\hline & Provincial industrialization status \\
\hline \multirow{5}{*}{$\begin{array}{l}\text { Job satisfaction and } \\
\text { well-being }\end{array}$} & Staff maintenance of dignity \\
\hline & Increased job satisfaction \\
\hline & $\begin{array}{l}\text { Lack of proper accountability conformed to the } \\
\text { statuses of provincial hospitals }\end{array}$ \\
\hline & Necessity of the staff families to possess welfare \\
\hline & Staff maintenance of dignity \\
\hline \multirow{5}{*}{ Nature of security } & Threats and crises \\
\hline & The need for a direct treatment, especially in crises \\
\hline & The need to maintain security \\
\hline & The need to respect security principles \\
\hline & $\begin{array}{l}\text { The need for full implementation of the adaptation } \\
\text { plan }\end{array}$ \\
\hline \multirow{8}{*}{ Delivery of services } & The need for special clinical investigations \\
\hline & Refusing to refer to Tehran \\
\hline & Existence of an empty capacity in the province \\
\hline & Ease of service delivery \\
\hline & Lack of appropriate medical center \\
\hline & Some provincial hospitals are primordial \\
\hline & $\begin{array}{l}\text { Lack of specialty and super specialty hospitals in } \\
\text { the province }\end{array}$ \\
\hline & Existence of local experts \\
\hline
\end{tabular}

Table 2. Classification of the codes derived from the question "What equipment and facilities are there to set up a hospital in this province?"

\begin{tabular}{|c|c|}
\hline Categories & $\begin{array}{r}\text { Extracted Codes } \\
\end{array}$ \\
\hline \multirow{5}{*}{ Human resources } & Abundant specialized human force \\
\hline & Skilled workers in related fields \\
\hline & Increased recruitment of specialists \\
\hline & $\begin{array}{l}\text { Existence of local employees with health fields of } \\
\text { study }\end{array}$ \\
\hline & $\begin{array}{l}\text { Existence of sincere and efficient workers in the } \\
\text { Department of Health }\end{array}$ \\
\hline \multirow{3}{*}{ Management } & $\begin{array}{l}\text { Cooperation of provincial officials in setting up a } \\
\text { specialized hospital }\end{array}$ \\
\hline & $\begin{array}{l}\text { Good interdepartmental collaboration in the } \\
\text { province }\end{array}$ \\
\hline & Empathy among managers in the province \\
\hline \multirow{5}{*}{$\begin{array}{l}\text { Physical space and } \\
\text { appropriate } \\
\text { facilities }\end{array}$} & $\begin{array}{l}\text { Existence of an appropriate physical space for } \\
\text { hospital establishment }\end{array}$ \\
\hline & $\begin{array}{l}\text { Existence of clinical centers capable of being } \\
\text { turned into a hospital through structural changes } \\
\text { and spatial developments }\end{array}$ \\
\hline & $\begin{array}{l}\text { Existence of modern and updated tools and } \\
\text { equipment }\end{array}$ \\
\hline & $\begin{array}{l}\text { Existence of large specialty and super specialty } \\
\text { facilities }\end{array}$ \\
\hline & Having the necessary infrastructure \\
\hline \multirow{3}{*}{ Service providers } & Lack of a specialized hospital in the province \\
\hline & Existence of a medical university in the province \\
\hline & $\begin{array}{l}\text { Possibility of taking advantage of the expertise of } \\
\text { the medical universities present in the province }\end{array}$ \\
\hline \multirow{2}{*}{$\begin{array}{l}\text { Integrity and } \\
\text { acceptability of } \\
\text { health care services }\end{array}$} & Public confidence in health centers \\
\hline & Existence of a sufficient number of patients \\
\hline
\end{tabular}

Table 3. Classification of the codes derived from the question: "what obstacles are there to set up a hospital in the province?"

\begin{tabular}{|c|c|}
\hline Categories & Extracted Codes \\
\hline \multirow{4}{*}{$\begin{array}{l}\text { Laws, rules, and } \\
\text { regulations }\end{array}$} & $\begin{array}{l}\text { Per capita of hospital beds approved by the } \\
\text { Ministry of Health }\end{array}$ \\
\hline & Terms and Conditions \\
\hline & Implementation of compliance plan \\
\hline & $\begin{array}{l}\text { Non-approval of hospital establishment by the } \\
\text { Ministry of Health }\end{array}$ \\
\hline \multirow{6}{*}{ Resources } & $\begin{array}{l}\text { Shortages of funds to build, equip, and develop } \\
\text { health centers }\end{array}$ \\
\hline & $\begin{array}{l}\text { Provision of specialized medical and nursing staff } \\
\text { Shortage of revenue sources }\end{array}$ \\
\hline & Shortage of Payvar personnel \\
\hline & Shortage of medical equipment \\
\hline & Difficulty of securing capital equipment \\
\hline & $\begin{array}{l}\text { Lack of surgery centers as the prerequisites for the } \\
\text { construction of hospitals in the province }\end{array}$ \\
\hline \multirow{3}{*}{$\begin{array}{l}\text { Costs and } \\
\text { inefficiencies of other } \\
\text { service providers }\end{array}$} & High cost of treatment \\
\hline & $\begin{array}{l}\text { Prohibitive costs of making hospital beds and } \\
\text { long process of hospital construction }\end{array}$ \\
\hline & Inefficiency of the military hospital \\
\hline \multirow{2}{*}{ Provincial status } & Low population of the province \\
\hline & Newness of the province \\
\hline
\end{tabular}

Table 4. Categorization of the codes extracted from the question "what are your expectations from officials and staff groups to set up a hospital?"

\section{Categories Extracted Codes}

Notification of hospital structure and organization Establishment of a specialty center and delivery of appropriate services

Review of hospital construction barriers and making efforts to remove them

Performance of Issue of the necessary permits to build a hospital trusteeship duties Multilateral support of setting up an updated surgery and supports to center as a preliminary step trusteeship to establish a provide hospital in the future

comprehensive A pursuit to obtain agreement in principle to build a services hospital

Presentation of expert opinions in setting up a hospital

Acceleration in the construction and establishment of a hospital

Having support for the establishment of a hospital

\begin{tabular}{ll}
\hline & $\begin{array}{l}\text { Supply of skilled manpower } \\
\text { Cooperation with the provinces to provide the } \\
\text { needed human resources from other academic } \\
\text { centers } \\
\text { Provision of the necessary space for the construction } \\
\text { of a hospital }\end{array}$ \\
$\begin{array}{l}\text { Supply of } \\
\text { resources }\end{array}$ & $\begin{array}{l}\text { Provision of specialist Payvar manpower in the field } \\
\text { of healthcare } \\
\text { Prioritization of the allocation of resources and } \\
\text { privileges to the deprived provinces }\end{array}$ \\
& $\begin{array}{l}\text { Provision of medical equipment } \\
\text { Provision of funds and credits for building a hospital }\end{array}$ \\
\hline
\end{tabular}

Of the mentioned codes extracted, codes 9 and 7 were dedicated to the tasks of stewardship and support to provide comprehensive services and supply of resources, respectively.

\subsection{Final Conceptual Model}

After conducting the interviews and using the techniques mentioned, a total of 4 questions: (1) the major reasons for setting up a hospital, (2) the necessary facilities needed to set up a hospital, (3) the barriers to setting up a hospital, and (4) expectations from the authorities to set up a hospital, were incorporated and thereafter, 18 categories and 87 codes were extracted after having many reviews and using experts' opinions (Figure 1). 


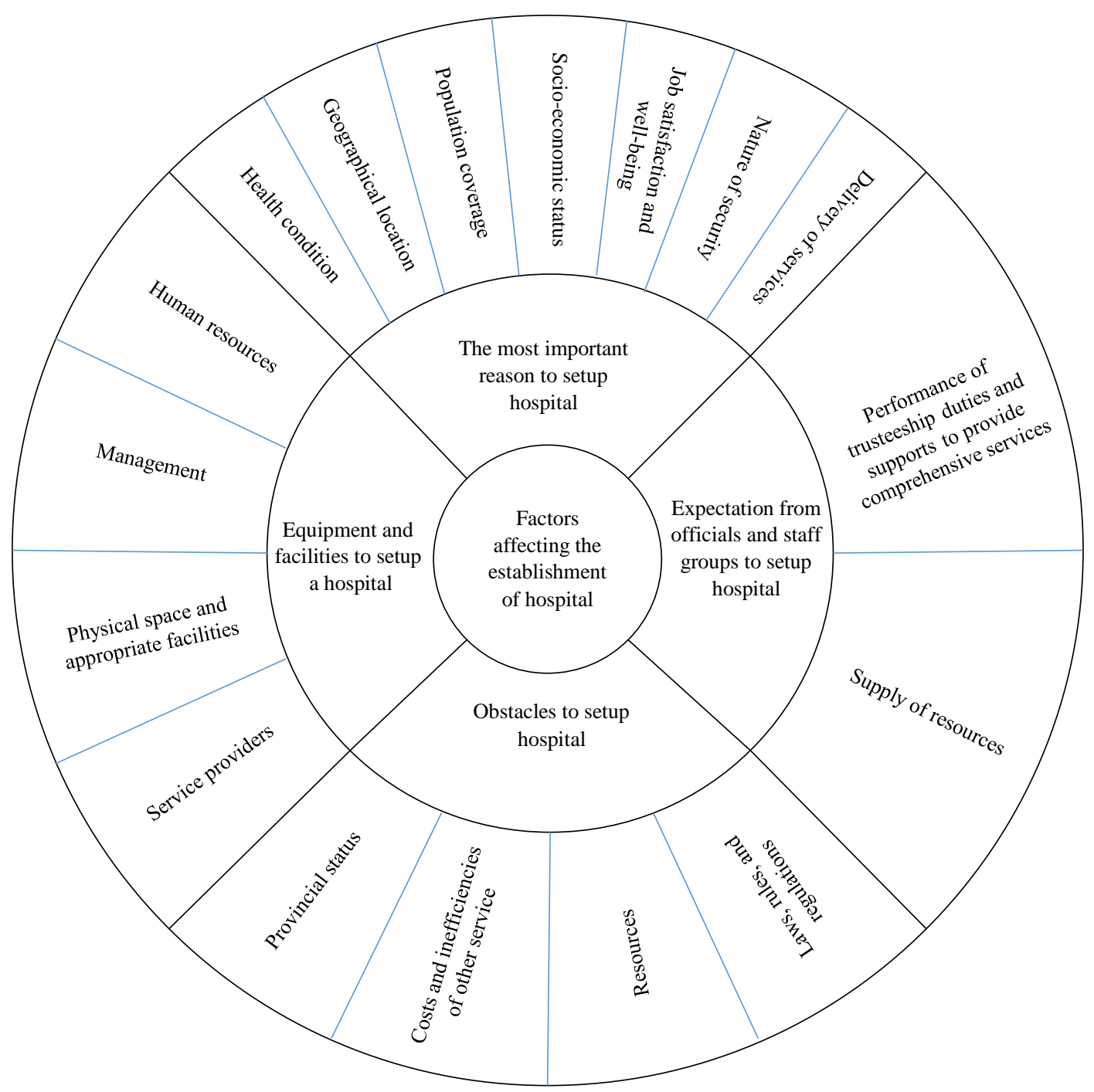

Figure 1. The conceptual model

\section{Discussion}

Health services are known as one of the main functions of health systems. In the meantime, providing comprehensive health services in the healthcare system with specific functional characteristics is very important.

The analysis of the interviews indicated that the issue of provision of services in terms of ease of access and equity in the reception of health services is also the focus of particular attention. As the subject was emphasized in Asefzadeh's [10] study, one of the problems faced in developing countries is that large and equipped hospitals are usually established in the capitals and urban centers, while access to services is not substantially taken into consideration.

Also, in another investigation conducted by Khayatan et al. [5], the focus was on the delivery of and equitable access to healthcare services. From among their suggestions, the establishment of health centers in proper locations can be referred to, so that the majority of people in the area can have easy access to those centers.

In addition, the reviews by Sharifzadgan [8] suggest the fact that the improvement of access requires optimal establishment and performance of the centers providing public health services. On the other hand, equal and fair access to and balanced distribution of public health services are regarded as an important base of social welfare for the different classes in a society.

Furthermore, in the study of Amerioon et al. [3], it was pointed out that the right to health care is one of the issues emphasized by the Universal Declaration of Human Rights and its importance is to the extent that it is considered by the constitutions of most countries. Equitable access to health care is a fundamental human right. In this regard, inequality in the geographical distribution of health resources has made it difficult for people to gain access to health services.

Some respondents stated that healthcare centers must be built in certain locations with special considerations, however, some already existing centers have been unfortunately established in areas that are extremely vulnerable in the event of war.

The socio-economic statuses of the provinces of this study, which includes the need for poverty alleviation and elimination of deprivation, equity in health services, and provincial industrialization status, were taken into consideration by the participants, as the reasons for setting up hospitals. Also, in the reviews by Gupta [12], this issue was proposed as key parameters in the design and planning of hospital establishment.

The subjects of geographic location and population 
coverage were also one of the most important issues admitted by the interviewees, who maintained that some hospitals are located along high-traffic routes due to the locations of some provinces. However, the high burden of a large number of immigrants, referred from other provinces, has caused current centers to fail as a result of the large volume of referrals and thus, they deemed it necessary to establish hospitals with appropriate capacities based on the mentioned perspective.

This issue which includes the main reasons to be considered before building hospitals, has been proposed in numerous studies $[5,8,10,11]$.

\subsection{The Main Obstacles in the Construction of Hospitals in Provinces}

The major issues that fall into this category include the following:

When reviewing the interviews, the issues of financing and human resources in the provincial hospitals were raised by the study participants as the key challenges. They believed that the high costs of building hospitals and the difficulty in providing skilled manpower, for some underprivileged provinces, are great obstacles to the construction of hospitals.

Numerous systematic reviews have been carried out on the provision of human and financial resources to establish hospitals:

For example, in Asefzadeh's study [10], it was noted that hospital, as a very costly unit within the body of health system, is generally a combination of manpower and other resources such as building, hardware, technology, materials, etc., all of which are employed to meet people's needs .

Furthermore, the results of Sharifzadegan's study [8] indicated that prior to the implementation of projects to build hospitals and healthcare centers, their effects and features must be evaluated from different dimensions and perspectives, thus deciding on the implementations with regard to issues such as funding and budgeting.

In this study, from the participants' views, hurdles to the establishment of hospitals include the existence of special laws, rules, and regulations. For instance, from the respondents' perspectives, the per capita of hospital beds approved, implementation of compliance plan, and frequent non-approval of the establishment of hospitals by the Ministry of Health were the major obstacles to this achievement.

Several studies have addressed the issue of laws and regulations. This is because if ignored, it becomes difficult to make progress in the direction of constructing hospitals, and results in the wastage of a significant portion of the limited resources in the health field.

\section{Conclusion}

In conclusion, besides illustrating the need and reasons for setting up hospitals in the provinces from the staff and managers' viewpoints, the findings of this research can serve as an operational guideline for the health system's policy-makers, who on this ground, will be able to adopt optimal decisions through their knowledge of the existing concrete issues, feasibility studies, and evidence-based managements at the provincial levels.

\section{Acknowledgments}

The authors express their gratitude to the "Clinical Research Development Unit" of the Baqiyatallah Hospital for their kind cooperation.

\section{Authors' Contributions}

All authors contributed equally in the preparation of this paper.

\section{Conflict of Interest}

No conflict of interest has been declared by the authors.

\section{References}

1. Millman M. Access to health care in America: National Academies Press; 1993.

2. Rajati F, Kamali K, Parvizy S. Public Health Customers' Experiences of Health Accessibility: A Phenomenological Study. Iran J Epidemiol. 2011;7(2):17-24.

3. Amerioon A, Mesgarpour Amiri M, Anabad A. Rate of inequality in kidney transplantation services access in Iran. J Crit Care Nurs. 2010;3(3):15-6

4. Sundquist J. Migration, equality and access to health care services. J Epidemiol Community Health. 2001;55(10):691-2. [DOI]

5. Khayatan M, Nasiri Pour A, Amini M, Mohamad Nejad S. The Effective factors on recievers' access to health care services in urban health care centers. Payavard Salamat. 2011;4(3):18-27. Persian

6. Jafari M, Rashidian A, Abolhasani F, Mohammad K, Yazdani S, Parkerton P, et al. Space or no space for managing public hospitals; a qualitative study of hospital autonomy in Iran. Int J Health Plann Manage. 2011;26(3):e121-e37. [DOI]

7. Ahmed S. Improving Access to Public Health Care Services-A Case Study on Dar es Salaam, Tanzania. Unpublished MSc Thesis, University of Twente Faculty of Geo-Information and Earth Observation (ITC). 2004.

8. Sharifzadegan M, Mamdohi M. A P-median-model-based Analysis of Spatial Inequality in Accessibility to Public Health Care Intended for Urban Health Development in Isfahan City. Soc Welf Q. 2010;10(37):265-85. Persian

9. Barnum H, Kutzin J. Public hospitals in developing countries: resource use, cost, financing: Johns Hopkins University Press; 1993.

10. Asefzadeh S. Responding to demand for inpatient care in the process of health development. J Res Med Sci. 2005;10(3):129-34.

11. Asefzadeh S. Assessing the need to establish new hospitals. World Hosp Health Serv. 1996;32(1):2-4.

12. Gupta K, Gupta SK. Modern trends in planning and designing of hospitals: Principles and practice: Jaypee Brothers Publishers; 2007. [DOI] 